\title{
Diabetes Distress, Depressive Symptoms and Type 2 Diabetes Management and Glycemic Control: the Mediating Role of Self-efficacy
}

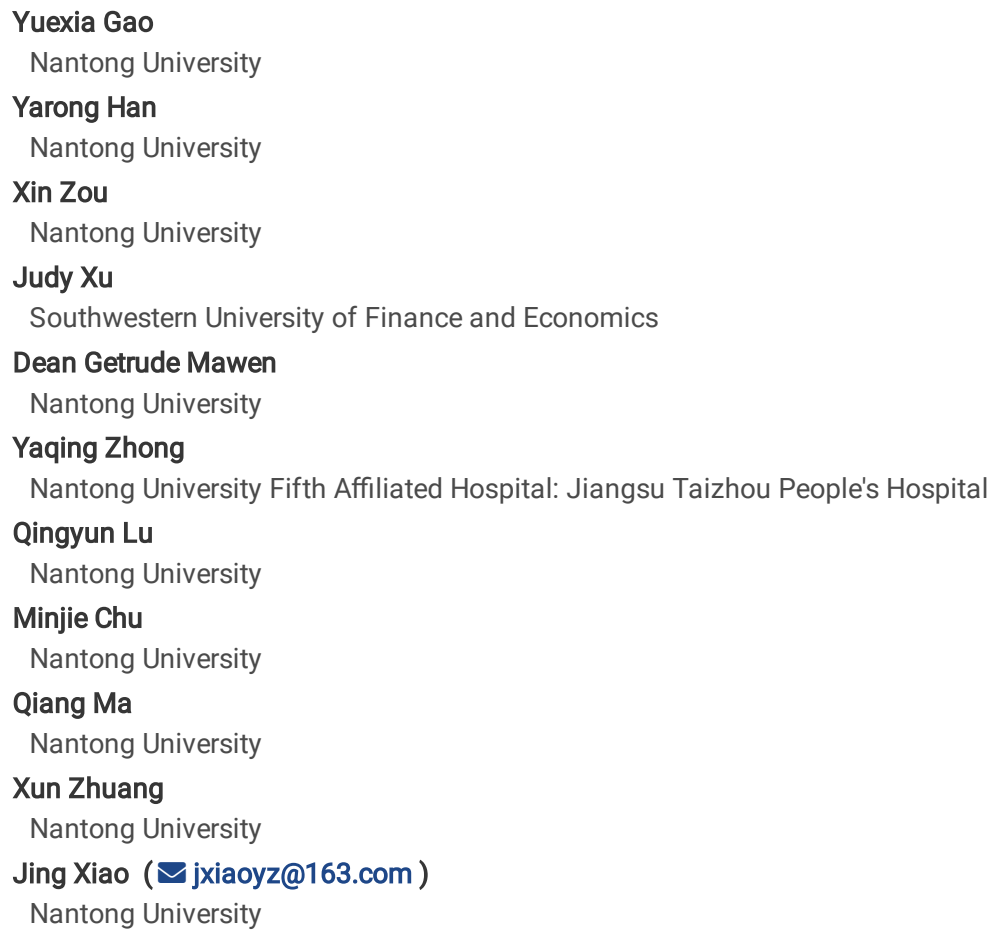




\section{Abstract}

Background: Diabetes distress has been distinguished from depressive symptoms in the linkages to type 2 diabetes management and glycemic control. There are few evidences in rural China untangled the underlying pathways among them. The aim of our study was to examine whether self-efficacy reduced the detrimental effects of psychological variables on diabetes outcomes such as self-care behaviors, glycemic control and health-related quality of life (HRQoL).

Methods: 1574 adults diagnosed with type 2 diabetes from 31 rural clinics in China were assessed for psychological variables, self-management and HRQoL. Hemoglobin A1c (HbA1c) data at 6 months after the survey were extracted from electronic medical records. Hierarchical regression model examined independent effects of psychological variables, self-efficacy on diabetes outcomes. KHB method and bootstrapping confidence intervals were employed to test the mediating effect of self-efficacy.

Results: Hierarchical regression analysis showed both diabetes distress and depressive symptoms were significantly related to diet and HRQoL, but not related to glycemic control and medication adherence. Depressive symptoms, but not diabetes distress, was directly associated with physical activity. Mediation analysis demonstrated self-efficacy mediated the relationships of both diabetes distress and depressive symptoms on self-care behaviors, glycemic control and HRQoL.

Conclusions: Self-efficacy may contribute to better diabetes outcome by ameliorating the effects of diabetes distress and depressive symptoms. Patients with psychological conditions may need tailored intervention that enhance self-efficacy to improve diabetes management.

\section{Introduction}

Diabetes is a complex and burdensome disease that requires the person with diabetes to make numerous daily decisions regarding food, physical activity, and medications[1]. Comorbid diabetes distress and depressive symptoms are prevalent emotional states in people with type 2 diabetes. Psychological problems could arise from stress of management diabetes and worrying about hypoglycemia and the complications of diabetes[2]. Diabetes distress is defined as a patients' concern about disease management, support, emotional burden and access to care[3], which views as part of diabetes spectrum and not a separate clinical psychopathology[4]. Studies of meta-analysis suggested overall estimated prevalence of diabetes distress among type 2 diabetes patients is $36 \%[5]$, but co-occurrence of depressive symptoms is about $20 \%[6]$. Some studies conducted both depressive symptoms and diabetes distress in type 2 diabetes individuals were associated with medication non-adherence and poor self-management[7], worse glycemic control[8] and lower health-related quality of life[9]. However, evidence also suggested diabetes distress had been distinguished from depressive symptoms, in the linkages to self-care activities and glycemic control. Two cross-sectional studies indicated that diabetes distress but not depressive symptoms, was associated with self-management and glycemic control $[3,10]$. However, another longitudinal study with 253 primary care type 2 diabetes patients suggested only depressive symptoms but not diabetes distress was associated with future diet, physical activity, and glucose testing self-care behaviors[11]. Clearly, the effect of diabetes distress and depressive symptoms on diabetes self-care and glycemic control are well studied but mixed results. Thus, the potential pathways among psychological factors and diabetes outcomes need to be studied further.

Self-efficacy, a critical concept of social cognitive theory (SCT), is related to one's belief and confidence in the ability to successfully perform a task and execute skills effectively[12]. A high degree of self-efficacy is essential for carrying out self-care behaviors. Considerable evidence supported self-efficacy had direct effect of improving diabetes self-management, medication adherence, metabolic outcomes and HRQoL[13, 14]. A meta-analysis of 775 studies concluded that self-efficacy was all consistence with all adherence behaviors (e.g. dietary, physical activity) and diet adherence was the most significant predictors of $\mathrm{HbA1c}[15]$. Interestingly, several recently research highlighted self-efficacy as a potential mediator in the links between depression or depressive symptoms and diabetes management[16-18]. One study with 371 type 2 diabetes patients in Malaysia found both diabetes distress and depressive symptoms had indirect effect on self-care activities via self-efficacy[19]. However, little is known about how psychological variables (e.g. depressive symptoms and diabetes distress) may stimulate diabetes management (e.g, physical activities, diet activities, glycemic control) at the same time, especially in the Chinese rural residents. Untangle the underlying pathways between psychological factors and specific diabetes self-management via self-efficacy is crucial.

Glycemic control is one of main goals of diabetes care. Recent studies focus more attention to possible mechanisms mediating the relationship between psychological variables and glycemic controls. Family members and friend support may contribute to better glycemic control by ameliorating the effects of diabetes distress[20]. Perceived control had mediated the effect of diabetes distress on medication adherence and glycemic control[16]. Self-efficacy of diabetes management as a mediator linked the relationship between depressive symptoms and glycemic control among males type 2 diabetes adults[17]. However, few empirical findings exist regarding the relationship between diabetes distress and glycemic control mediated via self-efficacy. One study with 254 Chinese type 2 diabetes patients found depressive symptoms had only indirect effect on glycemic control through diabetes self-management, but not via selfefficacy[18]. Therefore, studies are needed to empirically examine whether self-efficacy mediate the linkages among diabetes distress and glycemic control.

HRQoL as health being with type 2 diabetes has become increasingly important for diabetes control. A meta-analysis study has indicated that self-reported depressive symptoms in diabetes adults markedly impaired their HRQoL on several domains[21]. Little is known about the independent effect of diabetes distress on HRQoL among diabetes adults. One study of 193 Chinese Type 2 diabetes patients demonstrated diabetes distress was significant associated with glycemic control, obesity and quality of life[22]. Another study indicated diabetes distress and self-efficacy were related to HRQoL[23]. Poorer quality of life and depressive symptoms also had been associated with increased out-of-pocket payment for health service utilization and more likely to be impoverished[24]. Understanding how to distribute psychological care to diabetes patients with diabetes distress or depressive symptoms has important implications. Thus, further studies are deserved about the effect of diabetes distress and depressive symptoms on HRQoL and whether self-efficacy alleviate the two variables impact on HRQoL. 
Diabetes distress, depressive symptoms and self-efficacy are correlated. Their relationships with diabetes management and health outcomes may not be clearly observed unless they are examined in the same statistical model. Yet, to date, no studies to our knowledge have examined the potential pathways and interactions among psychological factors (both diabetes distress and depressive symptoms), behavioral variables (self-efficacy), diabetes management (e.g., healthy diet, physical activity, medication adherence), glycemic control and HRQoL in the same study, especially for primary care type 2 patients in rural China. The current study examines whether diabetes distress and/or depressive symptoms is directly associated with diabetes outcomes, such as diabetes management, sequent 6-month glycemic control and HRQoL among Chinese primary care adults with type 2 diabetes. In addition, we examine whether selfefficacy mediates both psychological factors and behavioral predictors in relation to diabetes outcomes. Based on social cognitive theory and aforementioned studies, we present a conceptual framework (Fig. 1) and employ regression-based mediation analysis to testify our hypothesis. We hypothesize that: (1) high level of diabetes distress and depressive symptoms would directly decrease diabetes management and health outcomes. (2)self-efficacy affected by diabetes distress and depressive symptoms, which, in turn, determines diabetes self-care behaviors, subsequent diabetes glycemic control and HRQoL.

\section{Materials And Methods}

\subsection{Study sample}

Observational follow-up study design was conducted in 5 rural clinics in Tongzhou district, 10 rural clinics in Dafeng district and 16 rural clinics in Haimen district in Jiangsu province, eastern China. All the clinics performed pilot reforms of family doctor signed contract service with type 2 diabetes patients. The inclusion criteria of clinics included: (1) 2-4 family doctors and/or nurses; (2) the numbers of type 2 diabetes patients signed the contract were more than 50; (3) the clinics agreed to participate in the study for at least 2 years. The inclusion criteria of participants included: (1) had a clinical diagnosis of type 2 diabetes $\geq 12$ months and age $\geq 30$ years; (2) patients agreed to participated in the full two-year study. Exclusion criteria included severe diabetes complications or functional deficits (e.g., blindness, dementia, psychosis). Eventually, 1574 adults with type 2 diabetes were recruited by cluster sampling from 31 rural clinics. Patients received a telephone call from the family doctors to explain the study purpose and eligible patients were invited and dated a specific time to complete face-to-face assessment. This study was approved by the ethics committees of Nantong University and informed consent was obtained from each participant. The data were collected between February and March 2019.

\subsection{Measures}

\subsubsection{Predictors}

The 17-item Diabetes distress Scale 17 (diabetes DDS-17) evaluated distress over the past month that was rated from 1 (not a problem) to 6 (a very serious problem). Items responses were averaged to generate a total score, with higher scores indicating greater diabetes distress. A mean item score $\geq 2$ (moderate distress) is considered a level of distress worthy of clinical attention[25]. A Chinese version of the diabetes DDS-17 was found to have good psychometric properties for internal consistency $(a=0.90)$ and test-retest reliability coefficient $(a=0.74)[22]$.

Depressive symptoms was measured by the 10-item Center for Epidemiologic Studies Depression Scale (CESD-10) short form[26]. CESD-10 assessed the extent to which individuals experienced depressive symptoms during the prior week on a 4-point Likert scale ranging from $1=$ rarely or none of the time ( $0-$ 1 day) to $4=$ most of the time ( $5-7$ days). The CESD-10 was high reliability and validity in Chinese middle age and elderly population $(a=0.82)[27]$. The CESD10 scores ranged from 1 to 30 , with higher scores indicating more severe depressive symptoms. Individuals who had scores 10 or above were classified as having depressive symptoms.

\subsubsection{Mediating variables}

Diabetes self-efficacy was measured using Lorig's 8-item diabetes self-efficacy scale $(\alpha=0.85)$ and test-retest validity of 0.80 [28]. Participants were requested to indicate their confidence in completing specific self-management tasks on a 5-point Likert scale, ranging from 1 (not at all confident) to 5 (totally confident). The scores of the scale is the mean of 8 items, with higher scores indicating greater self-efficacy.

\subsubsection{Dependent variables}

Diabetes self-management was assessed using the 11-item revised Summary of Diabetes Self-Care Activities (SDSCA)[29]. The SDSCA measures frequencies of specific self-care activities during the last week for six aspects of the diabetes regimen: general diet, specific diet, exercise, foot care, blood-glucose testing, taking medication and smoking. Respondents indicated the number of days during the past week that they followed their diets and physical activity regimens. All scale scores range from 0 to 7 , with high scores suggesting better self-management. The SDSCA has shown high reliability in measuring self-care behaviors of Chinese diabetes $(a=0.82)[30]$.

Adherence to diabetes medication was assessed using the Chinese version 8-item Morisky Medication Adherence Scale ( $a=0.65)$ (MMAS-8)[31]. Response choices are yes/no for item 1-7 and 5-point Likert response for last item. The total score of MMAS-8 ranged from $0-8$, with higher scores indicating of greater medication adherence. The scores are then categorized as low (less than 6), medium (6 to less than 8) and high (8) medication adherence subsequently.

HRQoL was assessed using EQ-5D-3L scale self-report questionnaires and has been validated Chinese population[32]. EQ-5D questionnaire provides utility values for 243 health states described using a system comprising five dimensions (e.g.mobility, self-care, usual activities, pain/discomfort, and anxiety/depression) and three levels ( $1=$ no problems, $2=$ some/moderate problems, $3=$ extreme problems) for each dimensions. Chinese Time trade-off value sets for EQ-5D was used to calculate EQ-5D index scores[33].

Hemoglobin A1c (HbA1c) data at 6 months after the survey were extracted from electronic medical records. HbA1c values less than $7 \%(53 \mathrm{mmol} / \mathrm{mol}) \mathrm{was}$ regarded as optimal glycemic control. 


\subsubsection{Control variables}

Control variables included age (trichotomized as equal to or below 59 years, $60-69$ ages, above 69 years), gender, education (trichotomized as 6 years or below, 7-9 years, 10 years or above), marriage (dichotomized as married, others), duration of diabetes (divided as four groups: 3 years or below, 4-6years, 7-9 years, 10 years or above) and numbers of chronic diseases (e.g. high blood pressure; cardiovascular, kidney problems, range 0-8).

\subsection{Data analysis}

We first conducted descriptive analyses of all variables (Table1), and examined the correlations among predictors, mediator of self-efficacy, and diabetes outcomes (Table 2), and then applied hierarchical ordinary least squares (OLS) linear regression models to explore the mediator self-efficacy on diabetes selfcare behaviors, glycemic control and HRQoL(Table 3a, 3b). KHB method was lastly used to estimate the total effect of the predictor variables diabetes distress and depressive symptoms on the outcome of diabetes management[34]. The total effect was divided into a direct effect of the predictor variables and an indirect effect of the mediator self-efficacy (Fig. 1).

Hierarchical regression models introduced variables according to our proposed conceptual model. In the models, psychological variables (diabetes distress and depressive symptoms) were predictor variables, diabetes outcomes (self-care behaviors, HbA1c and HRQoL) were dependent variables, while self-efficacy was the mediator. Age, gender, education, marital status, diabetes duration, numbers of chronic diseases were covariates with impact on predictors, the mediator and diabetes outcomes. They were controlled for in all the models.

Figure 1 depicts the assumptions that should be met to establish mediation: (1) The associations between predictor variables and the mediator self-efficacy should be statistically significant (path a). (2) The associations between the mediator self-efficacy and diabetes outcomes should be statistically significant, while the predictors and the mediator are added in the models (path b). Model 1 is used to test whether the mediator self-efficacy is affected by psychological variables (Fig. 1, path a). Models 2 and Models 3 are used to investigate the total effects (path c) of psychological variables on diabetes outcomes. From Models 2, Models 3 to Models 4 check whether the effect of psychological variables act through the mediator self-efficacy (indirect effect) or are unexplained by the mediator (direct effect). For mediation occurs, when the mediator is added (Models 4), the coefficient of mediator should be significant (path b), the coefficients of predictor variables on diabetes outcomes should diminish or disappear (direct effect, path c'). The Hierarchical estimation approach allows us to test how the impact of psychological variables may change once the mediator is applied for diabetes outcomes variables in the models.

In order to check the robustness of mediation effects, the bootstrapping mediation approach is used, with 95\% bias-corrected confidence intervals (Cls) based on a bootstrapping sample with 5000[35]. If the confidence interval of indirect effect does not contain zero, it indicates that the mediating role of self-efficacy is in fact different from zero. Analyses were performed using Stata software version 14. All statistical tests were two-tailed, with a set to 0.05 .

\section{Results}

\subsection{Sample Characteristics}

The sample was more female (67.60\%) and most were married (82.97\%), with a mean age of 66.33 (SD 8.97 ) years (Table 1). 69.28\% of participants had $\leq$ 6 years of education. The participants had an average of 1.43 chronic diseases and average duration of diabetes of 8.45 (SD 6.04 ) years. $21.60 \%$ of the participants had CESD scores of 10 or greater, $12.20 \%$ had diabetes DDS17 scores of 2 or greater and $45.17 \%$ had MMAS scores less than $8.43 .18 \%$ of participants achieved optimal glycemic control of $\mathrm{HbA} 1 \mathrm{c}<7.0 \%(53 \mathrm{mmol} / \mathrm{L})$.

\subsection{Correlations of psychological variables, behavioral variables and diabetes outcomes}

Correlations analyses conducted on between psychological variables, behavioral variables and diabetes outcomes (Table 2). Diabetes distress and depressive symptoms were significantly correlated $(r=0.26, P<0.001)$. Both DDS17 scores and depressive symptoms were significantly negative correlated with selfefficacy, physical activities, medication adherence and EQ-5D. However, psychological and behavioral variables were no significant correlated with HbA1c. Self-efficacy was significantly correlated with all psychological variables and diabetes outcomes $($ all $\mathrm{P}<0.001)$. Hence, self-efficacy was identified as a potential mediator.

\subsection{Hierarchical regression analysis}

Hierarchical regression analyses were conducted to test the effects of psychological variables on diabetes outcomes. As shown in Table 3 , Models 1 and Models 2 supported Hypothesis 1 that both diabetes distress and depressive symptoms were negatively associated with physical activity and HRQoL, but not related to HbA1c (path $\mathrm{c}$ in Fig. 1). However, only diabetes distress but not depressive symptoms was significantly and negatively affected diet and medication adherence, suggesting that the total effect of diabetes distress on healthy diet and medication adherence distinguished from depressive symptoms.

Fortunately, self-efficacy was significantly affected by diabetes distress and depressive symptoms (Model 1). While predictors and self-efficacy were included in the equations (Models 4), self-efficacy was significantly and positively associated with self-care behaviors and HRQoL, negatively associated with HbA1c, which indicated self-efficacy was a mediator, providing support for Hypothesis 2.

The changes in the estimated coefficients from Models 2 to Models 4 (path b and c' in Fig. 1), suggest the self-efficacy could compensate for the impact of diabetes distress on diabetes outcomes. The coefficients of diabetes distress in relationship to diet (from $\beta=-0.69, P<0.001$ to $\beta=-0.61, P<0.001$ ) and HRQoL (from $\beta=-0.06, P<0.001$ to $\beta=-0.02, P<0.01$ ) became smaller but still significant, which indicated self-efficacy partially medicated the relationships among them. Diabetes distress failed to predict physical activity and medication adherence after the self-efficacy was added (Models 4), suggesting self-efficacy played completely mediating role on the associations between depressive symptoms and the two self-care behaviors (physical activity, medication adherence). Likewise, the results in Models 4 showed self-efficacy had partial mediating effect of depressive symptoms in relation to physical activity (from

Page $4 / 11$ 
$\beta=-0.68, P<0.001$ to $\beta=-0.37, P<0.01$ ) and HRQoL (from $\beta=-0.13, P<0.001$ to $\beta=-0.11, P<0.01$ ), only mediating impact of depressive symptoms on diet, medication adherence. However unexpectedly, both diabetes distress and depressive symptoms only had indirect effect on HbA1c through self-efficacy.

\subsection{Mediation Analysis}

Results of KHB mediation analysis and bootstrapping confidence intervals testing indirect effect of psychological variables on diabetes outcomes are presented in Table 4. KHB regression results revealed self-efficacy significantly mediated the effect of both diabetes distress and depressive symptoms in relation to self-care behaviors, $\mathrm{HbA} 1 \mathrm{c}$ and HRQoL. The $95 \%$ bias corrected bootstrap Cls for indirect effects of psychological variables on diabetes outcomes through self-efficacy all excluded zero (Table 4), consisting with the KHB results and hierarchical regression results, which showed self-efficacy had a significant mediating role on diabetes management. The estimated coefficients of indirect effects indicated higher diabetes distress and severe depressive symptoms among type 2 diabetes patients were associated with lower self-efficacy, which in turn were associated with unhealthier diet, less exercise, poorer medication adherence, worse glycemic control and lower HRQoL. In addition, patients with higher diabetes distress had a significant direct effect for lower diet behavior (direct effect: $\beta=-0.61, P<0.001$ ) and HRQoL (direct effect: $\beta=-0.02, P<0.001$ ), but no significant direct effect for exercise, medication adherence and HbA1c. Those with depressive symptoms displayed significantly poor physical activities (direct effect: $\beta=-0.37, P<0.05$ ) and worse HRQoL (direct effect: $\beta=-0.01, P<0.001)$.

\section{Discussions}

Our study is the first to our knowledge to examine the mediating role of self-efficacy in the relationships of both diabetes distress and depressive symptoms on diabetes self-management, glycemic control and overall quality of life in the same study among adults with type 2 diabetes from primary care settings in rural China. Based on the conceptual model, our analyses reveal three main findings. First, both diabetes distress and depressive symptoms are independently associated with diet and HRQoL, but not significant direct associated with $\mathrm{HbA1c}$ and medication adherence. Physical activity is significant affected by depressive symptoms, but not by diabetes distress. Second, self-efficacy was significant related to self-care behaviors, HbA1c and HRQoL. Third, self-efficacy, as an independent mediator, significantly mediates the effect of both diabetes distress and depressive symptoms on diabetes self-management, glycemic control and HRQoL. The findings help elucidate key underlying mechanisms and pathways linking psychological factors and behavioral health with diabetes outcomes.

Diabetes self-management is crucial for metabolic control and quality of life. Consistent with previous studies[14], diabetes distress but not depressive symptoms had direct effect of healthy eating behavior, patients with depressive symptoms but not diabetes distress is related to poorer physical activities. Yet, it was not able to test whether self-efficacy mediated the relationships between the two affective variables and self-care behaviors. Devarajooh et al reported evidence to support self-efficacy as a mediator of the relationship between depressive symptoms, diabetes distress and the total score of self-care activities among type 2 diabetes using the structural equation model[19]. Neither the direct effect of both two variables with diabetes self-management nor the links between specific self-care activities (e.g. diet, physical activity) and distress or depression was found. Our new findings confirmed both diabetes distress and depressive symptoms had significant indirect effect of diet, physical activity through self-efficacy. Adherence to the prescribed medical regimen is an important goal in the management of diabetes and prevented complications. Gonzales et.al found diabetes distress, but not depression severity, was significantly related to medication adherence and mediation analyses demonstrated a significant indirect effect for depressive symptoms and medication adherence through self-efficacy and perceived control[16]. In contrast, the current findings found self-efficacy is convinced predictive of medication adherence and significant fully mediated the effect of both diabetes distress and depressive symptoms in related to medication adherence. Thus, the main contribution of our study is explaining possible pathway that how diabetes distress and depressive symptoms impact on self-care behaviors via self-efficacy.

In lines with previous reports[18,36], both diabetes distress and depressive symptoms were not significantly direct linked to glycemic control in the study. Different types of psychological variables measures (such as PHQ-9, CESD-10, diabetes DDS-17, PAID-5) may partly contribute to no significant association between depressive symptoms and glycemic control[36]. Another possible explanation was lower prevalence of diabetes distress (12.46\%) for patients in primary care settings couldn't detect the glycemic control difference in the cross-sectional study. Finally, potential mechanisms may explain the linkages between psychological variables and diabetes outcomes. For example, depression may decrease motivation to complete and maintain self-management behaviors that are protective against worsening of metabolic control[37]. Self-efficacy had been shown to significantly influence diabetes self-care behaviors, which in turn affected $\mathrm{HbA} 1 \mathrm{c}[14,30]$. Fortunately, our findings also suggest self-efficacy plays significant mediating roles of psychological variables (diabetes distress and depressive symptoms) in relation to $\mathrm{HbA1c}$.

Both diabetes distress and depressive symptoms were directly related to EQ-5D index scores in current study, similar to previous studies[9]. A longitudinal study of quality of life trajectory patterns among 455 type 2 diabetes from five clinics in Taiwan had shown diabetes distress and HbA1c level were important for determining participants in the QoL trajectory development[31]. Our study also found poor psychological conditions decreased adherence to self-care behaviors, especially for physical activities. A Bangladesh out-patient diabetes study had shown no-adherence to diet and exercise self-care practices were significant associated with lower quality of life[38]. A meta-analysis of 20 comparisons across 1892 subjects supported that self-management interventions improved health-related quality of life[39]. Furthermore, new evidence was added to understand how both diabetes distress and depressive symptoms impact on HRQoL through self-efficacy. In current study we found self-efficacy had significant mediating effects of psychological factors on HRQoL among type 2 diabetes patients. Self-efficacy enabled to maintain healthy behaviors, improve diabetes outcomes and promote positive well-beings. A recent meta-analysis study of ten trails with 1308 participants found self-efficacy-focused education in adults with diabetes probably reduced A1C, enhanced self-efficacy, regulated self-management behaviors and improved the QOL[40].

\section{Strengths And Limitations}


The present study has multiple strengths. The study provides a comprehensive framework to elucidate the relationships among psycho-social factors, behavioral factors and diabetes outcome based on social cognitive theory, and empirically explored multiple factors and pathways link these variables to one another. This is the first study to examine the mediation role of self-efficacy in the relationship among these variables in Chinese adults with type 2 diabetes and verify the indirect effect by KHB method. The KHB method decomposes effect of both discrete and continuous variables, applies average partial effects and provided analytically derived statistical tests. Second strength of this study is a relatively large sample size with high response rate in rural adults with type 2 diabetes. Finally, well-validated and specific instruments were used to measure multiple psychological and behavioral variables.

Several limitations should be kept in mind. First, cross-sectional design data prevents conclusions about the causal mediation and the ability to test the conceptual model among psychological variables, behavioral variables to diabetes management. Although we have described direct and indirect effects of psychological factors on diabetes outcomes, this causal mediation analysis is a convention of the statistical approach and should not be taken to imply that these cross-sectional analyses can address questions of directionality. Second, this study used a cluster sampling method, which added bias and decreased the representativeness of the sample. The study sample was relatively less educated and rural residents. Thus, the findings may not generalize to more diverse populations. Third, although we used well-validated and specific instruments, self-report measures may have introduced recall and social desirability bias. Finally, the prevalence of diabetes distress in this study is very low (12.46\%) and relatively higher optimal glycemic control of the participants (43.18\%). Thus, limiting direct effect of diabetes distress on glycemic control detected. Future studies should consider employing longitudinal design with patients from primary and tertiary hospitals and estimate changes in psychological conditions in relation to changes in diabetes management, glycemic control and HRQoL. Further studies also could test whether interventions to increase self-efficacy from existing primary health care to improve glycemic control and HRQoL among patients who experience high levels of psychological distress.

\section{Conclusions}

Self-efficacy may contribute to better diabetes self-care behaviors, glycemic control and HRQoL both directly and by mediating against the negative effects of diabetes distress and depressive symptoms. Diabetes distress and depressive symptoms had both direct and indirect effect on HRQoL, but only indirect effect of glycemic control through self-efficacy. The findings suggest that increased self-efficacy contribute to better diabetes management, metabolic control and HRQoL, particularly among individuals with elevated diabetes distress and depressive symptoms. Healthcare professionals should take consideration of psychological factors across the life span among diabetes adults, make assessment of affective factors, and addressed psychological problems upon identification. Mental health treatment in the context of primary care should be strengthened. Integrating behavioral and psychological interventions at primary care level could be prioritized for the right and most needy adults with type 2 diabetes to improve their diabetes management and health outcomes.

\section{List Of Abbreviations}

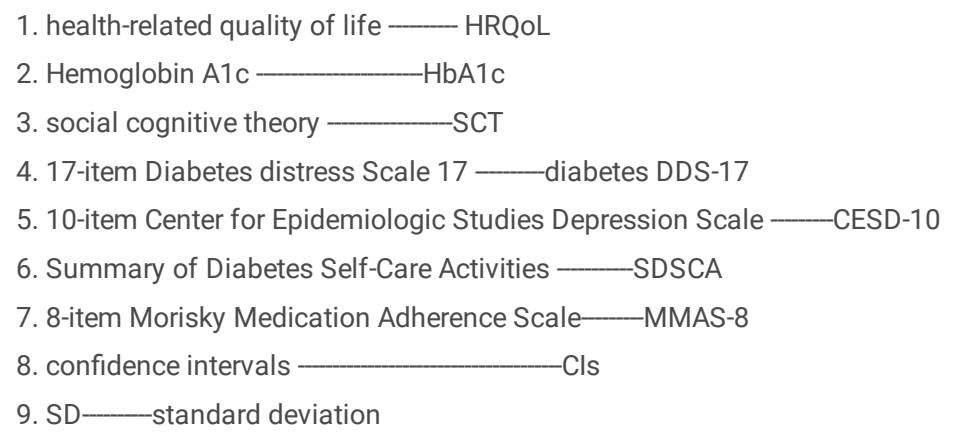

10. hierarchical ordinary least squares linear regression models---OLS

\section{Declarations}

\section{a. Ethics approval and consent to participate:}

This study was approved by the Ethics Committee of Nantong University, and each participant's informed consent was signed in person.

\section{b. Consent to publish:}

All authors of this study agree to publish.

\section{c. Availability of data and materials:}

The current data is not publicly available. If necessary, you can contact the corresponding author for permission.

\section{d. Conflicts of Interest:}

All authors have read and approved to the published version of the manuscript. The authors declare no conflict of interest.

\section{e. Funding:}


This research was funded by National Natural Science Foundation of China (grant No. 71603137); Social science foundation of Jiangsu Province(grant No. 19GLB026); Jiangsu Overseas Visiting Scholar Program for University Prominent Young \& Middle-aged Teachers and Presidents (2017).

\section{f. Author Contributions:}

G.Y. :conceptualization and writing-original draft preparation; H.Y. : writing of results and statistical analysis; Z.X.: investigation and writing of methods; Dean : supervision and language editing; Z.Y., L.Q. and C.M. :validation and formal analysis. M.Q., Z.X. and X.J. : methodology and writing-review and editing.

\section{g. Acknowledgments:}

The authors thank Jack Needleman and Zuofeng Zhang (University of California, Los Angeles, UCLA) for consulting on the data analytic and invaluable academic guidance. The authors thank the participants of the study for their contributions.

\section{References}

1. Powers MA, Bardsley J, Cypress M, Duker P, Funnell MM, Fischl AH, et al. (2015). Diabetes Self-Management Education and Support in Type 2 Diabetes: A Joint Position Statement of the American Diabetes Association, the American Association of Diabetes Educators, and the Academy of Nutrition and Dietetics. Diabetes Care, 38: 1372-1382.

2. Stuckey HL, Mullan-Jensen CB, Reach G, Kovacs BK, Piana N, Vallis M, et al. (2014). Personal accounts of the negative and adaptive psychosocial experiences of people with diabetes in the second Diabetes Attitudes, Wishes and Needs (DAWN2) study. Diabetes Care, 37:2466-2474.

3. Polonsky WH, Fisher L, Earles J, Dudl RJ, Lees J, Mullan J, et al. (2005). Assessing psychosocial distress in diabetes: development of the diabetes distress scale. Diabetes Care, 28:626-631.

4. Fisher L, Hessler D, Masharani U, Strycker L (2014). Impact of baseline patient characteristics on interventions to reduce diabetes distress: the role of personal conscientiousness and diabetes self-efficacy. Diabet Med, 31:739-746.

5. Perrin NE, Davies MJ, Robertson N, Snoek FJ, Khunti K (2017). The prevalence of diabetes-specific emotional distress in people with Type 2 diabetes: a systematic review and meta-analysis. Diabet Med, 34:1508-1520.

6. Roy T, Lloyd CE (2012). Epidemiology of depression and diabetes: a systematic review. J Affect Disord, 142 Suppl:S8-S21.

7. Gonzalez JS, Delahanty LM, Safren SA, Meigs JB, Grant RW (2008). Differentiating symptoms of depression from diabetes-specific distress: relationships with self-care in type 2 diabetes. Diabetologia, 51:1822-1825.

8. Schmitt A, Reimer A, Kulzer B, Haak T, Gahr A, Hermanns N (2015). Negative association between depression and diabetes control only when accompanied by diabetes-specific distress. J Behav Med, 38:556-564.

9. Carper MM, Traeger L, Gonzalez JS, Wexler DJ, Psaros C, Safren SA (2014). The differential associations of depression and diabetes distress with quality of life domains in type 2 diabetes. J Behav Med, 37:501-510.

10. Fisher L, Glasgow RE, Strycker LA (2010). The relationship between diabetes distress and clinical depression with glycemic control among patients with type 2 diabetes. Diabetes Care, 33:1034-1036.

11. Aikens JE (2012). Prospective associations between emotional distress and poor outcomes in type 2 diabetes. Diabetes Care, 35:2472-2478.

12. Bandura A (1977). Self-efficacy: toward a unifying theory of behavioral change. Psychol Rev, 84:191-215.

13. King DK, Glasgow RE, Toobert DJ, Strycker LA, Estabrooks PA, Osuna D, et al. (2010). Self-efficacy, problem solving, and social-environmental support are associated with diabetes self-management behaviors. Diabetes Care, 33:751-753.

14. Walker RJ, Smalls BL, Hernandez-Tejada MA, Campbell JA, Egede LE (2014). Effect of diabetes self-efficacy on glycemic control, medication adherence, self-care behaviors, and quality of life in a predominantly low-income, minority population. Ethn Dis, 24:349-355.

15. Brown SA, Garcia AA, Brown A, Becker BJ, Conn VS, Ramirez G, et al. (2016). Biobehavioral determinants of glycemic control in type 2 diabetes: A systematic review and meta-analysis. Patient Educ Couns, 99:1558-1567.

16. Gonzalez JS, Shreck E, Psaros C, Safren SA (2015). Distress and type 2 diabetes-treatment adherence: A mediating role for perceived control. Health Psychol, 34:505-513.

17. Cherrington A, Wallston KA, Rothman RL (2010). Exploring the relationship between diabetes self-efficacy, depressive symptoms, and glycemic control among men and women with type 2 diabetes. J Behav Med, 33:81-89.

18. Lin K, Park C, Li M, Wang X, Li X, Li W, et al. (2017). Effects of depression, diabetes distress, diabetes self-efficacy, and diabetes self-management on glycemic control among Chinese population with type 2 diabetes mellitus. Diabetes Res Clin Pract, 131:179-186.

19. Devarajooh C, Chinna K (2017). Depression, distress and self-efficacy: The impact on diabetes self-care practices. Plos One, 12:e175096.

20. Lee AA, Piette JD, Heisler M, Rosland AM (2018). Diabetes Distress and Glycemic Control: The Buffering Effect of Autonomy Support From Important Family Members and Friends. Diabetes Care, 41:1157-1163.

21. Ali S, Stone M, Skinner TC, Robertson N, Davies M, Khunti K (2010). The association between depression and health-related quality of life in people with type 2 diabetes: a systematic literature review. Diabetes Metab Res Rev, 26:75-89.

22. Ting RZ, Nan H, Yu MW, Kong AP, Ma RC, Wong RY, et al. (2011). Diabetes-related distress and physical and psychological health in chinese type 2 diabetic patients. Diabetes Care, 34:1094-1096.

23. Zhu Y, Fish AF, Li F, Liu L, Lou Q, (2016). Psychosocial factors not metabolic control impact the quality of life among patients with type 2 diabetes in China. Acta Diabetol, 53:535-541. 
24. Akena D, Kadama P, Ashaba S, Akello C, Kwesiga B, Rejani L, et al. (2015). The association between depression, quality of life, and the health care expenditure of patients with diabetes mellitus in Uganda. J Affect Disord, 174:7-12.

25. Fisher L, Hessler DM, Polonsky WH, Mullan J (2012). When is diabetes distress clinically meaningful?: establishing cut points for the Diabetes Distress Scale. Diabetes Care, 35:259-264.

26. Andresen EM, Malmgren JA, Carter WB, Patrick DL (1994). Screening for depression in well older adults: evaluation of a short form of the CES-D (Center for Epidemiologic Studies Depression Scale). Am J Prev Med, 10:77-84.

27. Lei X, Sun X, Strauss J, Zhang P, Zhao Y (2014). Depressive symptoms and SES among the mid-aged and elderly in China: evidence from the China Health and Retirement Longitudinal Study national baseline. Soc Sci Med, 120:224-232.

28. Loring K, Stewart A, Ritter P, Gonzalez V, Laurent D, Lynch J, (1996). Outcome measures for health education and other health care interventions. Thousand Oaks, Ca:stage.

29. Toobert DJ, Hampson SE, Glasgow RE (2000). The summary of diabetes self-care activities measure: results from 7 studies and a revised scale. Diabetes Care, 23:943-950.

30. Gao J, Wang J, Zheng P, Haardorfer R, Kegler MC, Zhu Y, et al. (2013). Effects of self-care, self-efficacy, social support on glycemic control in adults with type 2 diabetes. Bmc Fam Pract, 14:66.

31. Wang J, Bian RW, Mo Y (2013). Validation of the Chinese version of the eigh-item Morisky medication adherence scale in patients with type 2 diabetes mellitus. J Clin Gerontol Geriatr, 4:119-122.

32. Wang H, Kindig DA, Mullahy J (2005). Variation in Chinese population health related quality of life: results from a EuroQol study in Beijing, China. Qual Life Res, 14:119-132.

33. Liu GG, Wu H, Li M, Gao C, Luo N (2014). Chinese time trade-off values for EQ-5D health states. Value Health, 17:597-604.

34. Kohler U, Karlson KB, Holm A (2011). Comparing Coefficients of Nested Nonlinear Probability Models. The Stata Journal, 11:1-19.

35. Preacher KJ, Kelley K (2011). Effect size measures for mediation models: quantitative strategies for communicating indirect effects. Psychol Methods, 16:93-115.

36. Chew BH, Vos RC, Pouwer F, Rutten G (2018). The associations between diabetes distress and self-efficacy, medication adherence, self-care activities and disease control depend on the way diabetes distress is measured: Comparing the DDS-17, DDS-2 and the PAID-5. Diabetes Res Clin Pract, $142: 74-84$.

37. Egede LE, Osborn CY (2010). Role of motivation in the relationship between depression, self-care, and glycemic control in adults with type 2 diabetes. Diabetes Educ, 36:276-283.

38. Saleh F, Mumu SJ, Ara F, Hafez MA, Ali L (2014). Non-adherence to self-care practices \& medication and health related quality of life among patients with type 2 diabetes: a cross-sectional study. Bmc Public Health, 14:431.

39. Cochran J, Conn VS (2008). Meta-analysis of quality of life outcomes following diabetes self-management training. Diabetes Educ, 34:815-823.

40. Jing X, Wang J, Lu Y (2019). Self-efficacy-focused education in persons with diabetes: A systematic review and mata-analysis. Psychology Research and Behavior Management, 12:67-79.

\section{Tables}


Table 1

participants characteristics $(n=1574)$

\begin{tabular}{|c|c|}
\hline & mean $\pm S D / n(\%)$ \\
\hline Age, years & $66.33 \pm 8.97$ \\
\hline \multicolumn{2}{|l|}{ age } \\
\hline$\leq 59$ & $332(21.09)$ \\
\hline $60-69$ & $628(39.90)$ \\
\hline$\geq 70$ & 614(39.01) \\
\hline \multicolumn{2}{|l|}{ gender } \\
\hline male & $510(33.12)$ \\
\hline female & $1064(67.60)$ \\
\hline \multicolumn{2}{|l|}{ education } \\
\hline primary school and low & $1070(67.98)$ \\
\hline middle school & $389(24.79)$ \\
\hline high school and above & $115(7.33)$ \\
\hline \multicolumn{2}{|l|}{ marriage } \\
\hline married & $1306(82.97)$ \\
\hline others & $255(17.03)$ \\
\hline duration of diabetes & $8.45 \pm 6.04$ \\
\hline$\leq 3$ years & $293(18.61)$ \\
\hline $4-6$ years & $474(30.11)$ \\
\hline $7-10$ years & $356(22.62)$ \\
\hline$\geq 11$ years & $451(28.65)$ \\
\hline numbers of chronic diseases & $1.43 \pm 1.10$ \\
\hline total CESD & $5.63 \pm 5.66$ \\
\hline depressive symptoms (CESD $\geq 10$ ) & $340(21.60)$ \\
\hline DDS score & $1.42 \pm 0.46$ \\
\hline distressed (mean DDS $\geq 2$ ) & $192(12.20)$ \\
\hline \multicolumn{2}{|c|}{ glycemic control, A1c \% (mmol/L) $(\mathrm{n}=843)$} \\
\hline$<7.0$ & $364(43.18)$ \\
\hline $7.0-8.0$ & $201(23.84)$ \\
\hline$\geq 8.0$ & $278(32.98)$ \\
\hline \multicolumn{2}{|l|}{ medication adherence } \\
\hline $\operatorname{Low}(<6)$ & $279(17.73)$ \\
\hline Moderate $(<8)$ & $432(27.45)$ \\
\hline $\operatorname{High}(=8)$ & $863(54.83)$ \\
\hline
\end{tabular}


Table 2

Despritive statistics and simple correlations among predictors, mediators and diabetes outcomes.

\begin{tabular}{|c|c|c|c|c|c|c|c|c|c|c|}
\hline & mean(SD) & Range & $\begin{array}{l}\text { Cronbach's } \\
\mathbf{a}\end{array}$ & $\begin{array}{l}\text { DDS } \\
\text { score }\end{array}$ & $\begin{array}{l}\text { Depressive } \\
\text { symptoms }\end{array}$ & Diet & $\begin{array}{l}\text { Physical } \\
\text { activity }\end{array}$ & $\begin{array}{l}\text { MMAS } \\
\text { score }\end{array}$ & HbA1c & EQ-5D \\
\hline Self-efficacy & $\begin{array}{l}4.55 \pm \\
0.49\end{array}$ & $\begin{array}{l}1.75 \sim ~ \\
5.0\end{array}$ & 0.68 & $-0.37 \ddagger$ & $-0.23 \ddagger$ & $0.24 \ddagger$ & $0.25 \ddagger$ & $0.13 \ddagger$ & -0.06 & $0.24 \ddagger$ \\
\hline DDS score & $\begin{array}{l}1.42 \pm \\
0.46\end{array}$ & $\begin{array}{l}1.0 \sim \\
4.06\end{array}$ & 0.89 & 1 & $0.30 \neq$ & $-0.29 \ddagger$ & $-0.08+$ & $-0.06^{\star}$ & -0.01 & $-0.24 \ddagger$ \\
\hline $\begin{array}{l}\text { Depressive } \\
\text { symptoms }\end{array}$ & $\begin{array}{l}0.22 \pm \\
0.41\end{array}$ & $0 \sim 29$ & 0.87 & & 1 & -0.03 & $-0.12 \ddagger$ & -0.01 & 0.03 & $-0.39 \ddagger$ \\
\hline Diet & $\begin{array}{l}5.61 \pm \\
1.17\end{array}$ & $1 \sim 7$ & 0.60 & & & 1 & $0.14 \ddagger$ & 0.03 & 0.05 & 0.04 \\
\hline Physical activity & $\begin{array}{l}3.83 \pm \\
2.48\end{array}$ & $0 \sim 7$ & 0.67 & & & & 1 & -0.04 & -0.01 & $0.24 \ddagger$ \\
\hline MMAS score & $\begin{array}{l}6.85 \pm \\
2.06\end{array}$ & $0 \sim 8$ & 0.76 & & & & & 1 & $0.14 \ddagger$ & -0.04 \\
\hline $\mathrm{HbA} 1 \mathrm{c}$ & $\begin{array}{l}7.50 \pm \\
1.64\end{array}$ & $4 \sim 16.4$ & - & & & & & & 1 & -0.001 \\
\hline EQ5D & $\begin{array}{l}0.91 \pm \\
0.15\end{array}$ & $\begin{array}{l}-0.149 \\
\sim 1\end{array}$ & 0.73 & & & & & & & 1 \\
\hline \multicolumn{11}{|c|}{ Note: ${ }^{*} P<0.05 ;$ † $P<0.01$; $¥ \mathrm{P}<0.001$} \\
\hline
\end{tabular}

Table 3

Hierarchical regression models of distress, depressive symptoms, self-efficacy, self-care activities to diabetes outcome.

\begin{tabular}{|c|c|c|c|c|c|c|c|c|c|c|c|c|c|c|c|}
\hline & \multirow{2}{*}{$\begin{array}{l}\begin{array}{l}\text { Self- } \\
\text { efficacy }\end{array} \\
\text { Model } \\
1\end{array}$} & \multicolumn{3}{|l|}{$\operatorname{Diet}(\beta)$} & \multicolumn{3}{|c|}{ Physical activity( $\beta)$} & \multicolumn{3}{|c|}{ Medication adherence $(\beta)$} & \multicolumn{3}{|c|}{$\mathrm{HbA1c}(\beta)$} & \multicolumn{2}{|c|}{$\mathrm{EQ} 5 \mathrm{D}(\beta)$} \\
\hline & & $\begin{array}{l}\text { Model } \\
2\end{array}$ & $\begin{array}{l}\text { Model } \\
3\end{array}$ & $\begin{array}{l}\text { Model } \\
4\end{array}$ & $\begin{array}{l}\text { Model } \\
2\end{array}$ & $\begin{array}{l}\text { Model } \\
3\end{array}$ & $\begin{array}{l}\text { Model } \\
4\end{array}$ & $\begin{array}{l}\text { Model } \\
2\end{array}$ & $\begin{array}{l}\text { Model } \\
3\end{array}$ & $\begin{array}{l}\text { Model } \\
4\end{array}$ & $\begin{array}{l}\text { Model } \\
2\end{array}$ & $\begin{array}{l}\text { Model } \\
3\end{array}$ & $\begin{array}{l}\text { Model } \\
4\end{array}$ & $\begin{array}{l}\text { Model } \\
2\end{array}$ & $\begin{array}{l}\text { Moc } \\
3\end{array}$ \\
\hline \multicolumn{16}{|l|}{ Predictors } \\
\hline DDS Score & $-0.31 \neq$ & $-0.69 \ddagger$ & & $-0.61 \neq$ & $-0.35 \ddagger$ & & 0.19 & $-0.23 \ddagger$ & & -0.05 & -0.09 & & -0.21 & $-0.06 \neq$ & \\
\hline $\begin{array}{l}\text { Depressive } \\
\text { symptoms }\end{array}$ & $-0.18 \neq$ & & -0.09 & $0.20+$ & & $-0.68 \ddagger$ & $-0.37 \star$ & & -0.18 & -0.02 & & 0.03 & -0.01 & & $-0.1:$ \\
\hline \multicolumn{16}{|l|}{ Mediator } \\
\hline $\begin{array}{l}\text { Self- } \\
\text { efficacy }\end{array}$ & & & & $0.34 \ddagger$ & & & $1.33 \neq$ & & & $0.52 \ddagger$ & & & $-0.29+$ & & \\
\hline Observation & 1574 & 1574 & 1574 & 1574 & 1574 & 1574 & 1574 & 1574 & 1574 & 1574 & 843 & 843 & 843 & 1574 & 157. \\
\hline $\operatorname{Adj}-R^{2}$ & 0.173 & 0.093 & 0.016 & 0.111 & 0.024 & 0.031 & 0.089 & 0.046 & 0.050 & 0.058 & 0.048 & 0.048 & 0.052 & 0.080 & 0.16 \\
\hline$\Delta \operatorname{Adj}-R^{2}$ & - & 0.078 & 0.001 & 0.096 & 0.004 & 0.011 & 0.069 & 0.002 & 0.006 & 0.014 & - & - & 0.003 & 0.041 & 0.12 \\
\hline
\end{tabular}

Note: ${ }^{*} \mathrm{P}<0.05 ;+\mathrm{P}<0.01 ; \neq \mathrm{P}<0.001$.

DDS-Diabetes Distress Scale;

All the model controlled (age, gender, education, marital status, diabetes duration, numbers of chronic diseases). In the first step only covariates added in the the covariates explained $1.5 \%$ variance (Adj- $\left.R^{2}=0.015\right)$ of diet, $2.0 \%$ variance of physical activity (Adj- $\left.R^{2}=0.020\right), 4.4 \%$ variance of medication adherence $($ Ad 0.044 ), the covariates explained $3.5 \%$ variance (Adj- $\left.R^{2}=0.049\right)$ of $H b A 1 c, 7.0 \%$ variance of $E Q-5 D\left(A d j-R^{2}=0.039\right)$. 
Table 4

Mediation effect test of diabetes distress, depressive symptoms to self-care activities through self-efficacy.

\begin{tabular}{|c|c|c|c|c|c|c|c|c|c|c|c|c|c|c|c|c|}
\hline & Diet & & & & Physic & I activity & & & Medic & tion adh & rence & & $\mathrm{HbA1c}$ & & & \\
\hline & $\begin{array}{l}\text { Direct e } \\
(\mathrm{X} \rightarrow \mathrm{Y})\end{array}$ & fect & $\begin{array}{l}\text { Indirect } \\
(\mathrm{X} \rightarrow \mathrm{M}-\end{array}$ & $\begin{array}{l}\text { effect } \\
\text { Y) }\end{array}$ & $\begin{array}{l}\text { Direct } \\
(X \rightarrow Y)\end{array}$ & fect & $\begin{array}{l}\text { Indirect } \\
(\mathrm{X} \rightarrow \mathrm{M}-\end{array}$ & $\begin{array}{l}\text { effect } \\
\text { Y) }\end{array}$ & $\begin{array}{l}\text { Direct } \\
(X \rightarrow Y)\end{array}$ & effect & $\begin{array}{l}\text { Indirect } \\
(\mathrm{X} \rightarrow \mathrm{M}-\end{array}$ & $\begin{array}{l}\text { effect } \\
Y)\end{array}$ & $\begin{array}{l}\text { Direct } \\
(X \rightarrow Y)\end{array}$ & ffect & $\begin{array}{l}\text { Indirec } \\
(\mathrm{X} \rightarrow \mathrm{M}\end{array}$ & $\begin{array}{l}\text { effect } \\
\rightarrow Y)\end{array}$ \\
\hline & $\beta$ & $\begin{array}{l}95 \% \\
\mathrm{Cl}\end{array}$ & $\beta$ & $\begin{array}{l}95 \% \\
\mathrm{Cl}\end{array}$ & $\beta$ & $\begin{array}{l}95 \% \\
\mathrm{Cl}\end{array}$ & $\beta$ & $\begin{array}{l}95 \% \\
\mathrm{Cl}\end{array}$ & $\beta$ & $95 \% \mathrm{Cl}$ & $\beta$ & $95 \% \mathrm{Cl}$ & $\beta$ & $95 \% \mathrm{Cl}$ & $\beta$ & $95 \%($ \\
\hline DDS score & $-0.61 \neq$ & $\begin{array}{c}-0.74 \\
-0.49\end{array}$ & $-0.10 \ddagger$ & $\begin{array}{l}-0.16 \\
-0.05\end{array}$ & 0.19 & $\begin{array}{l}-0.07 \\
0.46\end{array}$ & $-0.41 \ddagger$ & $\begin{array}{l}-0.57 \\
-0.29\end{array}$ & -0.05 & $\begin{array}{l}-0.27 \\
0.18\end{array}$ & $-0.16 \neq$ & $\begin{array}{l}-0.28 \\
-0.10\end{array}$ & -0.21 & $\begin{array}{l}-0.49 \\
0.06\end{array}$ & $0.12^{\star}$ & $\begin{array}{l}0.01, \\
0.22\end{array}$ \\
\hline $\begin{array}{l}\text { Depressive } \\
\text { symptoms }\end{array}$ & $0.20 \dagger$ & $\begin{array}{l}0.05 \\
0.34\end{array}$ & $-0.06 \ddagger$ & $\begin{array}{l}-0.20 \\
-0.09\end{array}$ & $-0.37^{\star}$ & $\begin{array}{l}-0.68 \\
-0.07\end{array}$ & $-0.24 \ddagger$ & $\begin{array}{l}-0.35 \\
-0.15\end{array}$ & -0.02 & $\begin{array}{l}-0.28 \\
0.24\end{array}$ & $-0.10 \ddagger$ & $\begin{array}{l}-0.22 \\
-0.08\end{array}$ & -0.01 & $\begin{array}{l}-0.28 \\
0.26\end{array}$ & $0.06^{*}$ & $\begin{array}{l}0.01, \\
0.12\end{array}$ \\
\hline
\end{tabular}

Note: ${ }^{*} \mathrm{P}<0.05 ;+\mathrm{P}<0.01 ; \neq \mathrm{P}<0.001$

all the model controlled control variables (age, gender, education, marital status, diabetes duration, numbers of chronic diseases).

$95 \% \mathrm{Cl}=95 \%$ bias-corrected bootstrapping confidence interval.

\section{Figures}

\section{Psychological variables}

Diabetes Distress

Depressive Symptoms

\section{Behavior variables \\ Self-efficacy}

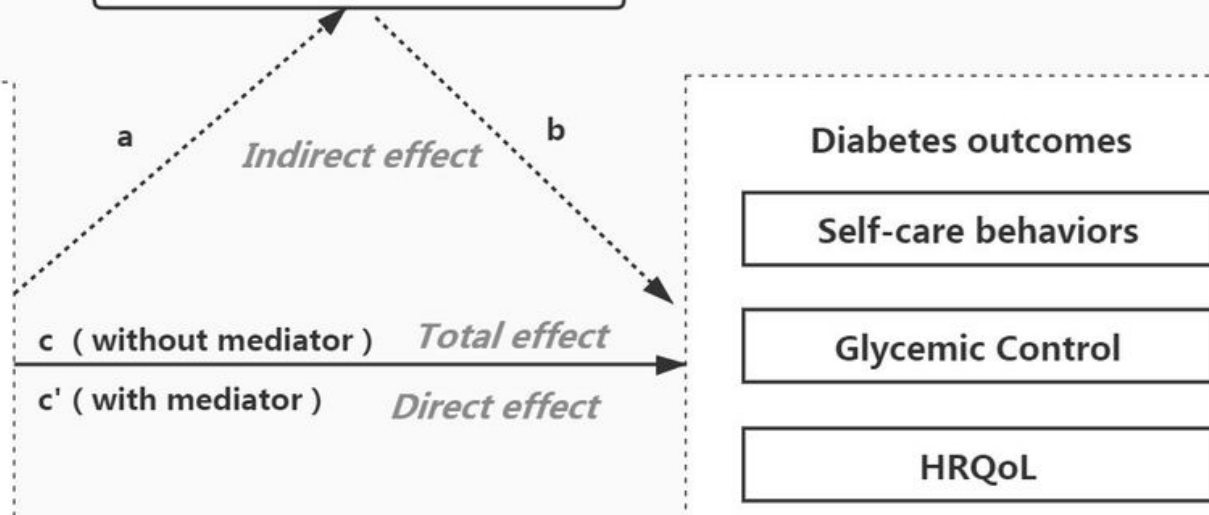

Figure 1

Study conceptual model for proposed the relationships between psychological variables, behavior variables and diabetes outcomes. Dotted lines show a potential pathway mediated by self-efficacy. 